\title{
PASCAL BOYER: DEN GANSKE HISTORIE OM AL RELIGION (NOGENSINDE)
}

\author{
Jeppe Sinding Jensen
}

Blandt religionsforskningens særheder hører, at den ikke så hurtigt påvirkes af nye strømninger. De fleste religionsforskere har som regel så rigeligt at gøre med deres empiriske data, at de ikke hopper med på hvad som helst. Når de tager noget nyt ind, så har det som regel en vis levetid - f.eks. er strukturalisme en gangbar teori og metode i religionsvidenskaben, hvor den andre steder omtales som '70'er-videnskab' og for længst er overhalet af et hav af andre teoridannelser, der i stort omfang også går uden om religionsvidenskaben. Hvis man leder efter nye og slagkraftige 'paradigmer' i religionsvidenskaben, er der ikke meget at vælge imellem. Den seneste og mest radikale nyskabelse er uden tvivl den kognitionsteoretisk funderede religionsforskning. Man kan på den ene side sige, at den er en videreudvikling af religionspsykologien, for så vidt man beskæftiger sig med religion som primært et mentalt, dvs. et individuelt og universelt, fænomen. På den anden side er der så radikale ændringer både i henseende til forskningens teoretiske objekt, dens empiriske materialer og dens metoder, at lighederne med de mere klassiske former for religionspsykologi hurtigt hører op. Den kognitionsvidenskabeligt funderede religionsforskning udføres da også kun i ringe omfang af de ellers kendte religionspsykologer, hvorimod 'almindelige' psykologer, antropologer, religionshistorikere, lingvister og andre har sat sig for at undersøge, hvad kognitionsforskningen kan bidrage med i religionsvidenskaben. Det kan dog for ikke-specialister være svært at få øje på den nye forskning, da den overvejende er blevet udfoldet i artikelform, men heldigvis udkommer der også monografier og i enkelte tilfælde nogle, som kan læses af den ikke-indviede. En sådan bog er Pascal Boyers Religion Explained. The Evolutionary Origins of Religious Thought (2001). Forfatteren kan om nogen identificeres med den 'kognitive vending' i religionsforskningen, så det er ikke hvem som helst, der er tale om. Derfor først lidt om forfatteren, så om bogen og hans projekt med udblik til nogle generelle problemer i den kognitive religionsvidenskab.

Pascal Boyer er professor i individuel og kollektiv psykologi ved Washington University i St. Louis i USA. Men først studerede han filosofi i Frankrig, var siden på feltarbejde i Cameroun og siden stipendiat i Cambridge i en del år. Derefter vendte han tilbage til Frankrig og arbejdede ved MRASH's ('Maison Rhône-Alpes des Sciences de l'Homme') laboratorium for eksperimentel lingvistik og psykologi i Lyon. Biografien er interessant, fordi hans arbejde på afgørende vis har drejet sig meget klart væk fra en fransk antropologisk orientering henimod en tydelig anglo-amerikansk empiristisk og psykologisk position. Boyer er efterhånden ganske velkendt som den franske antropo$\log$, der har introduceret begreber som 'mod-intuitiv' og 'domænespecifik' i religions- 
forskningen og på dansk grund vel især i Århus, hvor 'kognitionsparadigmet' har sat sig godt fast. Det skyldes oprindeligt personlige kontakter mellem forskere - med senere udveksling af ph.d.-studerende til følge. E. Thomas Lawson var manden, som først formidlede kontakt til bl.a. Boyer og siden har instituttet i Århus været en del af den række af kognitionsinteresserede religionsforskningsmiljøer, som især findes i Finland og i USA. ${ }^{1}$ Derfor mener lærerstaben ved Afdeling for Religionsvidenskab ved Aarhus Universitet, at 'kognition' nu har sin plads i disciplinen 'forskningshistorie' på overbygningsuddannelsen, og kognition indgår også som et væsentligt aspekt af satsningsområdet 'Religiøs Narrativitet, Kognition og Kultur', som blev sat i gang af Det Teologiske Fakultet i 2002. ${ }^{2}$ Så der er ingen tvivl om, at kognition er noget af det nye i religionsforskningen. En vis trompeteren har der også været i visse kredse, for nu synes vejen endelig banet for et vaskeægte videnskabeligt paradigme, der kan legitimere religionsforskning som noget, der fortjener opmærksomhed, autoritet og ikke mindst forskningsbevillinger. Triumfalismens fortalere er dog også blevet mødt med skepsis, fra hovedrysten over de terminologiske krumspring til bekymring for endnu en bølge af psykologisme inden for social- og humanvidenskab.

Mange har i de senere år præsenteret forskning og lærde værker, hvor titlen viser at forfatteren nu er i gang med den afgørende behandling af denne eller hin sag; mange titler indeholder ord som 'rethinking', 're-inventing' - fælles er, at suffikset '-ing' antyder, at de er i gang med et projekt. Men Boyer taler om noget ganske andet: Religion Explained med præteritum suffiks '-ed' og i passiv. Det betyder, at forklaringen på religion nu er givet og dermed slut. Måske. Som religionsforskere vil vi selvfølgelig gerne have forklaringer af og på det, vi forsker i, men vi har nok en formodning om, at religion er en sag, som er for omfattende at forklare på en gang. Så måske er det kun noget af religionen, som nu er forklaret og ikke det hele, som undertitlen The Evolutionary Origins of Religious Thought også antyder. Uden at afsløre hele handlingen og konklusionen skal det bemærkes, at Boyer har konstrueret en kompliceret kæde af forbundne fænomener, som alle har den underfulde egenskab, at de lader sig forklare ved hjælp af hans analytiske og teoretiske apparat. I den forstand er bogens struktur meget velgennemtænkt; men det betyder også. at mangt og meget, som det kunne have været interessant at få belyst og diskuteret, ikke bliver det. Til beroligelse for de religionsforskere, og ikke mindst studerende, som endnu ikke har læst bogen, kan det afsløres, at Boyer absolut ikke har gjort religionsforskningen overflødig, og han har slet ikke forklaret alt om religionen, dens væsen og oprindelse, selv om hans værk slutter med en 'faktaboks' om The Full History of All Religion (Ever). Men han har forklaret en hel del om den religiøse tankes evolutionære oprindelse, og det er noget, som kan medvirke til at gøre religionsforskningen teoretisk mere interessant. Jeg skal her vise, hvad dette

\footnotetext{
${ }^{1}$ Lawson, som hører hjemme på University of Western Michigan, har været på adskillige besøg ved instituttet. Boyer har også deltaget i en konference på vort institut. Begge er nu redaktører af Journal of Cognition and Culture (Brill, Leiden).

${ }^{2}$ Se herom Årsskrift 2003, Det Teologiske Fakultet ved Aarhus Universitet, s.76-81 og satsningsområdets hjemmeside på www.teo.au.dk
} 
mere er, og hvordan Boyer bidrager til religionsforskningen; positivt som negativt. Der er en del problemer i hans projekt, som gør, at vi dels må sige fra, dels må supplere med noget ganske anderledes. Derfor først en gennemgang af bogens substans, derpå en præsentation af en række af Boyers hovedpointer. Så følger kritikken, som er ganske omfangsrig, men det skyldes også Boyers egen ambition om at præsentere et radikalt anderledes paradigme, hvorfor dette må underkastes en nærmere prøvelse, der ikke er krævet i en gængs anmeldelse. Til sidst nogle spørgsmål om relevans og anvendelse.

\section{Religion Explained. The Evolutionary Origins of Religious Thought}

I religionsforskningen har man længe tabuiseret spørgsmålet om religionens oprindelse, og det af gode grunde, for der er blevet sagt meget sludder om den sag. Men religion er jo kommet et eller andet sted fra, og derfor er Boyers undertitel interessant, fordi det handler om den religiøse tankes (i ental) oprindelse i evolutionen. Boyer lægger stærkt ud med at erklære samtlige alment kendte ideer om religionens oprindelse og årsag for ugyldige (s. 4-31): Religion forklarer ikke noget om verden, den giver ikke trøst og lindring, den bidrager ikke til social stabilitet, ej heller er den bare en illusion eller overtro forårsaget af epistemisk dovenskab. Hans radikale forkastelse af de gængse ideer bliver dog noget modereret længere fremme i bogen, for selv om de ikke er oprindelse eller årsag til religion, kan de godt være funktioner af den. For Boyer handler religion især om de ikke-observerbare størrelser og agenter, der har særlige evner og kræfter, og de vigtigste er dem, der har 'strategisk information', som kan bruges af mennesker. Så i en vis forstand bliver Boyer inden for den intellektualistiske religions-forklarings perspektiv.

For at give en rimelig beskrivelse af hans projekt og bogens forløb vil jeg parafrasere de ni 'Progression Boxes', som han har indsat i teksten på strategiske argumentationsknudepunkter. Den første 'boks' (s. 18) siger, at trangen til at forklare universet ikke er religionens oprindelse; man kan kun forklare religiøse begreber, hvis man beskriver, hvordan de bruges af individer ('individual minds'). Den nye vinkel er derfor at antage, at religiøse begreber er påvirket af hvordan hjernens mekanismer ('inference systems') frembringer forklaring, uden at vi ved det. I boks 2 (s. 22) konkluderes det, at religiøse begreber ikke altid giver trøst og lindring, og at udfrielse fra dødelighed ikke helt er den universelle trang, som man ofte har formodet. Religiøse begreber er forbundet med vore emotionelle systemer, som er knyttet til oplevelse af livstruende omstændigheder. Endeligt er vore følelsesformer ('emotional programs') en del af den evolutionære arv, og det kan forklares, hvordan de påvirker vore religiøse begreber. I den følgende boks 3 (s. 27) går Boyer imod udbredte funktionalistiske ideer om religion, for nu siges det, at religion ikke kan forklares med et behov for at holde sammen på samfundet eller opretholde moral. Sådanne behov skaber ganske enkelt ikke institutioner. Social handling og moral er dog væsentlige for vores tilegnelse af religion og for, hvordan den påvirker menneskers adfærd. En anden vinkel: Studiet af den sociale bevidsthed ('the social mind') kan vise os hvordan mennesker har bestemte forventninger om det sociale liv og om moral, og hvordan disse forventninger forbindes med overnaturlige begreber. I boks 4 om reli- 
gion og fornuft hedder det, at fornuftens søvn ('the sleep of reason') hverken er nogen forklaring på religion eller på, at tro ikke kun er en passiv accept af, hvad andre hævder. Derfor skal vi forstå, hvad der gør den menneskelige bevidsthed så selektiv i forhold til hvilke overnaturlige påstande, den finder plausible.

Efter kritikken af de gængse ideer går Boyer over til sin egen hypotese om domænespecifik kognition. I boks 5 (s. 106) siger han, at opfattelse og forståelse af vore omgivelser fordrer slutninger ('inferences') og gæt om forskellige aspekter af objekter omkring os. Bevidstheden ('mind') er sammensat af specialiserede systemer, som producerer inferenser om disse forskellige aspekter. Objekter i forskellige ontologiske kategorier aktiverer forskellige dele af disse specialiserede systemer. Hvert inferens-system er selv sammensat af endnu mere specialiserede neurale strukturer. Ikke længe efter dukker boks 6 op (s. 115) om udvikling og 'det specifikke': Først siger Boyer, at inferenssystemerne får os til at være opmærksomme på bestemte vink ('cues'), og systemerne frembringer slutninger ud fra disse vink. Dette sker allerede fra den tidligste barndom. Alle begreber udvikles som færdigheder og efter artspecifikke principper. Derfor er evolution relevant for forståelse af den mentale arkitektur. Senere, i boks 7 (s. 128) udfoldes dette yderligere. Specifikke inferenssystemer blev skræddersyet i den naturlige selektion ud fra deres bidrag til at løse bestemte problemer i vore forfædres omgivelser. Hvis man vil beskrive dem, er det formålstjenligt at kombinere teoretiske forudsigelser ud fra en evolutionsteoretisk baggrund med eksperimentelle beviser. Væsentlig for vores art er tilpasning til socialt liv, eftersom information (især den som gives af andre) er vores særlige økologiske niche. Den sidste boks 8 (s. 135) siger, at den bevidsthed, som kræves, for at man kan have religion, er den standardarkitektur, som vi alle har i og med, at vi tilhører samme art. Religion fordrer altså ikke nogen særlig mentalitet eller form for bevidsthed. På grund af evnen til fra-kobling ('de-coupling') og specialisering er den menneskelige bevidsthed særligt følsom over for en række kulturelle objekter ('gadgets'). Derfor vil man forvente, at religiøse begreber er succesrige i det omfang, de aktiverer flere inferenssystemer.

Så langt så godt, men det giver ikke i sig selv megen mening. Derfor skal jeg give et kort rids af, hvad det er, Boyer på dette grundlag hævder. Det sidste punkt (i boks 8) er vigtigt, for det er en grundlæggende tese, at jo flere inferenssystemer, som aktiveres, desto større kognitiv effervescens - for nu at bruge et udtryk fra en tradition, som Boyer vender ryggen. ${ }^{3}$ Religion er således karakteristisk ved, at både forestillinger og handlinger inden for dens univers udløser mange kognitive energier, og at de derfor er bemærkelsesværdige og nemmere at huske. Det skyldes, at religion indeholder så meget som umiddelbart forekommer os 'naturstridigt' - det som han kalder det 'modintuitive'. Det kræver en kommentar.

\footnotetext{
3 'Effervescens' var Émile Durkheims betegnelse for den 'følelsernes opbrusen', som ritualdeltagere kan opleve i de mere emotionelt ladede rituelle situationer.
} 


\section{Det intuitive og det mod-intuitive}

Det intuitive og det mod-intuitive handler om medfødte kognitive ontologiske kategorier og de inferenssystemer, der er knyttet til dem. Til trods for, at han hævder det modsatte (s. 3, 112f), må man karakterisere Boyer som nativist, dvs. overbevist om, at vi fødes med en række kategorier indkodet $\mathrm{i}$ hjernen, en indre viden om ontologiske kategorier (hvad der findes) og til dem kobles nogle standardinferenser (s. 61-70), som er domænespecifikke. ${ }^{4}$ Vi har naturligt indbygget forventninger til, hvad disse objekter som tilhører specifikke kategorier kan og ikke kan: intuitive vidensprincipper og inferenssystemer, som tænder og slukker, alt efter hvad vi har med at gøre. Derudfra organiserer vi vores øvrige viden. Teorien hænger på studier af nyfødte og meget små børns reaktioner på stimuli, for jo yngre forsøgspersoner, det passer på, jo længere tilbage kommer vi, ikke blot i den ontogenetiske, individuelle udvikling, men også i den fylogenetiske artsevolution (antager Boyer). Der fremføres argumenter om neurale strukturer og funktioner, som betinger, at kognitionen opererer på forskellig vis i forhold til, om et erfaringsobjekt hører til det fysiske, det biologiske og det psykiske domæne eller en kombination af dem. Det fører til muligheden af at opstille et katalog over følgende ontologiske kategorier: person, genstand (artefakt), dyr, plante og ikke-levende naturgenstande. ${ }^{5}$ Til disse kategorier er der specifikke forventninger, som så typisk brydes i den religiøse forestillingsverden, f.eks. hvor slanger kan tale, hvor guder er allestedsnærværende og evige, men ellers kan have antropomorfe træk, som inuitmytologiens Havkvinde, der siddende under havet holder på fangstdyrene, fordi der er gået kludder i den symbolske udveksling. Det er de religiøse forestillingers egenart, at de altid indeholder brud på de intuitive ontologiske forventninger. "Religiøse begreber indeholder altid information som er mod-intuitiv i forhold til den kategori, der er tale om" (s. 64f). Det eneste menneskelige træk, som altid overføres på overnaturlige væsner er bevidsthed (s. 163). Der er en god portion stædig fransk oplysningsrationalitet i Boyers kritik af religiøs bevidsthed som fantasier om åndelige væsner. Hans tilgang er ubønhørligt naturalistisk. Religion er et utilsigtet resultat af menneskets kognitive plasticitet: religion får vi, når hjernen 'går amok'. Men fænomenet religion er så udbredt, at det næsten må siges at være naturligt. ${ }^{6}$ Det er også karakteristisk, at Boyer ikke taler om, hvad de indfødte hævder eller

\footnotetext{
${ }^{4}$ Han er nærmest vrissen over at skulle forklare sig som ikke-nativist, men da han på intet tidspunkt erklærer, at kategoriseringskompetence grundlæggende er tillært, kan hans udtalelser om begreber osv. kun tages til indtægt for et nativistisk synspunkt. Han burde have været meget mere klar omkring dette spørgsmål, da det er selve grundlaget for hans hypotese, som er på spil. Nativismekritik fremføres gennemtænkt i Elman et al. 1996, hvor der i øvrigt ikke står et eneste ord om religion, som er et 'noget', der ligger langt hinsides de allerfleste kognitionsforskeres horisont.

${ }^{5}$ Dette katalog er også beskrevet og forklaret i Boyer 1998.

${ }^{6}$ I et on-line udkast til en kommende artikel skriver Boyer ganske klart om hans ændrede syn på religion: “(i) de involverede processer er langt mere komplekse end de troendes egne udtrykkelige beretninger om deres egne trosforestillinger, (ii) det som gør religiøse tanker 'naturlige' kan meget vel være aktiviteten i en hel samling af distinkte mentale systemer, snarere end af en central motivation, og (iii) $\mathrm{i}$ hvert af disse systemer er de religiøse tanker ikke nogen dramatisk afvigelse fra, men et forudsigeligt biprodukt af almindelige mentale funktioner." Se også Boyer 2003.
} 
om, at ideer om det 'overnaturlige' skulle være et etnocentrisk, vestligt eller et oplysningsfilosofisk påhit. Alle kulturer, uden undtagelse, kender udmærket skellet mellem det naturlige, det intuitive og det mod-intuitive. Så i den forstand er Boyer også ærkeuniversalist.

Evolutionen har forsynet os med et særligt udviklingspotentiale for de mentale evner. Men selv om vores kapacitet for fiktion er næsten ubegrænset, så viser det sig, at religiøse ideers dannelse, udbredelse og reproduktion begrænses af visse kognitive faktorer - ikke mindst fordi noget er bedre eller nemmere at huske end andet. Hans program var oprindeligt (1990) at udvikle en stærk teori om hukommelse, også kulturelt og traditionsbestemt. Det førte siden (1994) til udviklingen af ideen om religiøse forestillingers 'naturlighed'. Faktisk burde vi alle være religiøse, hvis Boyer har ret. Når vi måske ikke er det eller er det på forskellig måde, så må det skyldes sociale, kulturelle, historiske eller i det hele taget kontingente forhold, men det problem går han udenom. Han er heller ikke interesseret i, om de kognitive processer i relation til religion udgør et system, om de afspejler verden eller forklarer den. Det er irrelevant, for som han før har anført, skal "beskrivelsen omhandle reelle kognitive processer, snarere end de abstrakte beskrivelser af deres mulige epistemiske konsekvenser" (1994, 53). Det væsentlige for Boyer er netop, at religion som kognitiv praksis består i aktivering af mange mentale mekanismer, og at det i sig selv har en slags tiltrækningskraft og udløser en form for psykologisk, mental effervescens ('flow', 'party-stemning'...). Og det skal blankt indrømmes, at de fleste religioner er psykosociale systemer, der spiller på alle tangenter. Ved man det ikke, er det på tide at tage på feltarbejde.

\section{Den ganske historie om al religion (nogensinde)}

Forklaringen på den naturlighed, som religionens forestillingsverden fremstår med, fremlægges i den sidste faktaboks The Full History of All Religion (ever). Vi får at vide, at mennesker til (næsten) alle tider har talt om ting og sager; fiktive og sådanne som ikke var direkte observerbare, for det kan 'the modern mind' i kraft af sin symboliseringsevne. Iblandt al talen er der noget, der fanger vores opmærksomhed, fordi det overskrider vores almindelige epistemiske intuitioner. Den slags kan huskes, og det er godt stof til at lave historier om øer, som flyder; dyr, som taler osv. Det er fiktion, men det handler om agenter, og det åbner mulighed for en masse inferenser: Er de fiktive agenter ligesom andre usynlige og farlige ting? Det kan vi som art næsten ikke lade være med at tænke, fordi vor (under-)bevidsthed er drejet ('tuned') ind på det.

Visse forestillinger indeholder antagelser om, at de mod-intuitive agenter har en særlig, måske endda total, information, f.eks. om andre mennesker. Så kan man tildele dem (de usynlige agenter) viden om andres moralsk og socialt relevante handlinger. Ligeledes bliver det let at knytte forklaringer på held og uheld til dem, fordi der er en tilbøjelighed til at opfatte begivenheder som handlinger, som noget eller nogen er årsag til. Derfor tildeles de usynlige agenter kraft, magt og evne til at tildele ulykker osv. Dette er især vigtigt, når det handler om døden, som er et kognitivt problem for mennesket. Død skaber frygt, inkompatible intuitioner, på baggrund af vores evolutionære 
erfaringer bl.a. som bytte for rovdyr. På det grundlag er det logisk at forestille sig udvikling af ritualer - i sig selv meningsløse handlinger (for Boyer) - alene fordi undladelse af sådanne handlinger kan føre til ulykke og straf.

Eftersom mange ritualer udføres i sammenhænge, hvor den sociale interaktion ikke har nogen indlysende egenskaber eller formål, vil disse agenter derfor let kunne forekomme at være selve det sociale livs kerne. Når gruppen er stor nok, vil der være nogen, som er bedre end andre til at frembære overbevisende budskaber på vegne af de modintuitive agenter. Sådanne mennesker kan derfor tænkes at have en anden natur end andre i gruppen. Derved får de særligt privilegerede ritualroller. Hvis gruppen tilmed er skriftbrugende, vil nogen (eksperter) på et tidspunkt (sandsynligvis) begynde at fiksere ideerne, gøre dem mere abstrakte, mindre kontekst- og lokalitetsbetingede. For at beholde fortolkningsmonopolet og de fordele, som følger med, vil eksperterne danne monopoler, lav eller andre markedsorienterede grupper. Men deres versioner af begreberne vil ikke være kognitivt optimale, og derfor vil der opstå afstand mellem flertallets religiøse forestillinger, med spontane inferenser, som ikke harmonerer med de skriftbaserede doktriner; det som Boyer kalder 'teologisk korrekthed'?

Sådan siger Boyer. Det er historien om al religion, nogensinde. Men, som Boyer bemærker, er det ikke nogen rigtig historie. ${ }^{8}$ Meget af det synes man i øvrigt at have hørt før, der er alt fra Hume til Marx og Malinowski osv. Unik er kombinationen og den knudrede teoretiske underbygning; han taler selv om kognitionens mentale kældre. Men der er megen interessant læsning undervejs bl.a. om de religiøse specialister og deres politiske ambitioner og markedsøkonomiske ageren: Det handler om at skabe 'brands', noget som 'forbrugerne' (menigheden) tror, de har brug for, fordi de religiøse tjenesteydelser i sig selv er ganske overflødige. Direkte grum, men overbevisende, er hans forklaring på religiøs fundamentalisme (s. 292-96). Den fundamentalistiske vold (fysisk som psykisk) er afledt af koalitionsprincippet, som er grundlaget for den sociale kohærens, hvor gruppetvang styrker gruppen og sikrer mod frafald - afhopning skal gøres så dyr som overhovedet muligt (f.eks. Jehovas Vidner). Den fundamentalistiske vold er nemlig primært rettet mod gruppens egne medlemmer og fjendtlighed over for andre er blot et af midlerne til spektakulær demonstration af gruppens grænser. Derfor er fundamentalistiske grupper så offentligt synlige, selv om deres doktriner taler om inderlighed, gudsfortrøstning osv.

Slutbemærkningerne angår tilfældigheden i religionens oprindelse, for ifølge Boyer er der ikke tale om noget religiøst instinkt, ingen særlig religiøs tilbøjelighed i bevidstheden, intet religiøst modul i hjernen. Religiøse mennesker er ikke forskellige fra ikkereligiøse, og religiøs erfaring er ikke noget særligt, som Boyer forklarer i et mindre

\footnotetext{
${ }^{7}$ Ikke blot er der tale om korrekthed, men også om teologisk 'kedsomhed'. Teologi er ganske enkelt ikke spændende nok for almindelige mennesker, og så springer de på astrologi, shamanisme og andet med højt oplevelsesniveau. Dette aspekt behandles i Lawson og McCauleys nye bog (2002) som "the tedium effect", i diskussion med Whitehouse (2000) og dennes skelnen mellem doktrinære og imagistiske religionsformer. Det er de sidste, som har størst tag i deltagerne.

${ }^{8}$ Måske snarere en fabel, som f.eks. Freuds hypotese om Urhorden.
} 
opgør med traditionen fra William James. ${ }^{9}$ Religiøs tro er ganske enkelt bivirkninger af almindelige mentale funktioner, og derfor konkluderer han, at vi bedre forstår de mange fascinerende aspekter af vores mentale arkitektur ved at studere den menneskelige tilbøjelighed til religion: "One does learn a lot about these complex biological machines by figuring out how they manage to give airy nothing a local habitation and a name." Dermed slutter den 330 sider lange vandring, som følges af Further Readings, en del noter, bibliografi og et ganske omfangsrigt og anvendeligt indeks.

\section{Kritiske intuitioner}

Min kritik vil måske synes hård, urimelig eller næsten direkte negativ, men da Boyer selv så udmærket gør opmærksom på alt det positive, nye og brilliante i hans projekt og værk, men på ingen måde kan siges at øve selvkritik, er det på sin plads at give det forførende projekt nogle usødede bemærkninger med på vejen. Noget, som ganske irriterer denne anmelder, er, hvad jeg ville kalde 'Day 1-syndromet'. Bortset fra udvalgte nyere bidrag, der direkte støtter hans kognitionsteoretiske projekt, mangler det forskningshistoriske landskab eller bagtæppe. Boyer synes slet ikke at være klar over, at det som han arbejder på, har en historie, eller også er han bevidst eklektiker, men det gør ikke sagen bedre i metodologisk forstand. Her er intet om Freud, Durkheim, Malinowski eller noget andet, som ligger før den 'kognitive revolution' bortset fra den lille kritik af William James mod slutningen af bogen. Noget af det, han bruger, synes efterhånden forældet, bl.a. hans computer-analogier, hvor f.eks. tanker og fortolkning bliver til 'computations' og 'programs'. Han ser ud til ligefrem at gøre sig umage for ikke at komme til at anvende gængs terminologi. Der er end ikke reference til helt almindelige psykologiske begreber som attribution eller projektion(steori). Det forekommer næsten forskningsetisk uholdbart, eller også er det et udslag af inkompetence, begge dele er problematiske. Det er under ingen omstændigheder læservenligt. Eller måske er det et (misforstået) forsøg på læservenlighed at skrive en bog til 'ikke nogen' - den forudsætningsløse læser uden baggrund i noget specifikt fagligt felt.

Hertil skal føjes, at Boyer er et glimrende eksempel på kultur-eliminativisme, hvor hvert individ virkelig er en ø. Boyer vil, visse steder også med rette, gøre op med tidligere forsknings tendens til reifikation og essentialisering af kultur og kulturer - en forskning som ofte havde en tilbøjelighed til at gøre kulturer til selvstændige, transcendente agenter med en egen form for vilje og målrettethed. Men der er ingen tvivl om, at han går for vidt; for efter at have afskaffet kultur (s. 34ff) med en bemærkning om, at kulturelle grænser ikke er naturlige og derfor irrelevante (!), må han alligevel benytte sig af kultur i resten af bogen. Han låner Dan Sperbers materialistiske og epidemiologiske kulturbegreb (s. 45f), hvor kultur ganske enkelt består i en vis lighed mellem enkeltindividernes mentale 'forestillingsindhold' og praksis, når individerne er 'besat' af de

\footnotetext{
${ }^{9}$ Mystikeres beretninger om særlige, intense religiøse oplevelser sammenholdes af Boyer med neurovidenskabens opdagelse af lignende 'tilfælde' hos ikke-religiøse patienter som resultat af manglende kommunikation mellem forskellige dele af hjernen (s. 309). Så er mystik da godt og vel 'af-mystificeret'.
} 
samme memer. ${ }^{10}$ Kultur er derfor 'ikke andet end' (reduktionistens yndlingsudtryk) en vis ensartethed og lighed i en populations mempulje, og en lighed kan jo ikke, siger Boyer (s. 36), have nogen kausal kraft. Derfor kan man ifølge Boyer ikke tale om, at kultur er noget, man deler: "This is why it is very confusing to say that people share a culture, as if culture were common property. We may have strictly identical amounts of money in our respective wallets without sharing any of it" (s. 35f). Argumentet er lige så fladpandet, som det er forførende, for hvad ville den enkeltes penge være værd, hvis ikke vi delte en økonomi. ${ }^{11}$ Boyer interesserer sig kun for det, som refererer til individet, de kognitive mekanismer og hvad dertil hører inden for organismens grænser. Hvad der så måtte kunne følge deraf, er mindre vigtigt. Det ligner, som parallel, en interesse for metabolisme uden noget hensyn til gastronomi. Men så er det underligt, at han ikke forholder sig til en lang række teoretikere, der udfordrer den klassiske individcentrering og de efterhånden udtjente computeranalogier om bevidsthed. Her kunne man f.eks. nævne neurologen Antonio Damasio og biologen Jaak Panksepp. Antropologen Edwin Hutchins og filosoffen Andy Clark er også fraværende. Hvor er Terrence Deacon eller Jerome Bruner? Det er som om han maler sig op i et hjørne, hvor der kun er plads til ham og nogle få med identiske synspunkter. Hvis Boyer var studerende ville han få at vide, at sådan kan man ikke undgå at forholde sig til den eksisterende forskning eller kritikere af det paradigme, man foretrækker at alliere sig med. Der bliver også sjældent sat navn på alle de kultur- og religionsforskere, som skulle tage så grundigt fejl og som derfor ansvarsfrit kan hænges ud. Det er ikke rimeligt.

\section{Psykologismens genkomst?}

Boyers vision kan karakteriseres som noget, der ligner en krydsning mellem 70'er kognitionspsykologi og klassisk cartesiansk dualisme. Ideelt synes kognition for ham at foregå i hjerner i krukker: der er fornem adskillelse mellem res cogitans og res extensa, mellem 'mind and matter' ${ }^{12}$ Han går let og elegant uden om de nyere konstruktivistiske og interaktionistiske ideer om personens grundlag; i dag er en person ikke, hvad den var for 50 år siden. Det selvberoende og udelelige individ, som noget ('sjæl?'), der er indeholdt i en organisme, er blevet alvorligt dekonstrueret andre steder, også af antropolo-

\footnotetext{
${ }^{10}$ Sperbers materialistiske kulturopfattelse består ganske enkelt $i$ at en population har analoge 'repræsentationer' ('forestillinger') og at disse er 'materielle' fordi de er i hjernen: "mental representations are brain states described in functional terms" $(1996,26)$. Sperber springer også let og elegant over enhver kritik af hans position - den er jo ikke ny. Sperber er en slags guru i kredsen omkring 'triumfalisterne'. Førhen var han strukturalist, men det er han ikke længere stolt af (at have været).

${ }^{11}$ Tak til Lars Albinus for inspiration til behandling af dette punkt hos Boyer. Se Albinus' arbejdspapir: 'Sprog, kultur og kognition' på www.teo.au.dk/html/rv-sem/ritualis/Sprog.html

${ }^{12}$ Boyer er bevidsthedsteoretisk materialist (som Sperber) i den forstand, at han identificerer bevidsthed ('mind') med hjernen ('brain') og forstår mentale processer som computerlignende. Men hermed bliver det gamle 'sjæl-legeme' problem til en ny dikotomi mellem det kognitive og verden 'udenfor' - alt det som giver 'inputs' til vore indre 'inferens-maskiner'. Metodisk afsløres dette af ambitionen om at studere kognition uden at tage hensyn til hverken fysiske eller sociale omgivelser, for slet ikke at tale om hele det symbolsk-kulturelle univers - eller bare kroppen.
} 
ger, men det fører ikke til nogen refleksion hos Boyer. Bogen forekommer derfor også at være baseret på et problematisk psykologisk teorigrundlag, hvor en del af de væsentlige teoretiske og analytiske begreber hænger og svæver som abstrakte konstruktioner og ikke som de empirinære og deskriptive kategorier, som han selv hævder, de er. Det gælder centrale sager som skabeloner ('templates'), programmer ('programs') og ontologiske kategorier ('ontological categories') - de er ikke udbredte emner i kognitionspsykologisk litteratur og han må derfor selv forklare, hvad han mener. Det kunne tyde på stor videnskabelig originalitet, men det kan også være slap metode. ${ }^{13}$ Som eksempel på den teoretiske uklarhed kan man også tage selve hans opfattelse af begreber ('concepts'). Hans begreb om begreber er psykologiserende enøjet: begreber er simpelthen noget, som vi har inde i hovedet eller de er 'evner' ('skills'). ${ }^{14}$ Det samme synes at gælde for kategorier, der ligesom prototyper er kognitive størrelser, som med større eller mindre attraktionskraft dirigerer vore forestillinger rundt i den mentale manege. Alment filosofiske overvejelser om begrebers, kategoriers og typers ikke-mentale og intersubjektive eksistens er ikke anliggender, der optager forfatteren (de har dog holdt en del filosoffer til ilden i mindst et par årtusinder). Det er igen, fordi han holder sig til en strengt individualistisk metodologi og det er nok ikke videnskabsfilosofisk holdbart $i$ forhold til hans ærinde. Han har fat i noget religionsvidenskabeligt brugbart, men projektet omkranses af for mange afværgemekanismer i forhold til anden forskning.

Hertil kan føjes problemet med de 'ontologiske kategorier', som har deres helt egen problematik. Det er interessant, at Frank Keil ikke optræder i biografien, når han findes i bogens index og dér kun sammen med Michael Kelly i en artikel fra 1985. På side 89 får vi at vide, at Barrett og Keil har testet gudsopfattelser tværkulturelt, men uden videre henvisninger. Det er ellers et vigtigt punkt for hele argumentationen omkring forholdet mellem teologisk korrekthed og de spontane religiøse begreber i den intuitive psykologi. Side 108 anføres vigtige resultater fra forskningen i børns ideer om levende væseners substans, men med ganske overfladisk reference og ikke til Keils hovedværk (1979). På side 158 er der heller ingen henvisning til de åbenbart igen for argumentationen vigtige undersøgelser, som Barrett og Keil har foretaget, og som bygger på resultater af Keils tidligere arbejde. Keil er vigtig, fordi han har lagt hele grundlaget for Boyers 'ontologiske kategorier' og domæner ud fra en række studier af børns opfattelser af erfaringsobjekters tilhørsforhold til 'naturlige klasser'. Keil var inspireret af bl.a. Noam Chomskys teori om medfødte sprogevner og fik så ideen til at se, om filosoffen Fred Sommers sprogfilosofiske arbejde kunne have psykologiske konsekvenser. ${ }^{15}$ Keil tog en sprogfi-

\footnotetext{
13 'Template' er et eksempel på et begreb, som han bruger ganske anderledes, end man ellers har gjort. Med 'template' mener Boyer 'opskrift' på eller regler for, hvordan en kategori intuitivt forbindes med bestemte forventninger, at f.eks. en person er levende, har legeme, vilje osv. ... og hvor så (f.eks.) zombier og spøgelser er 'krænkelser' ('violations') af de typiske forventninger efter opskriften. En af de bedre forklaringer med eksempler findes i Boyer \& Ramble 2001, 537f.

${ }^{14}$ På den måde ender f.eks. matematik som et psykologisk fænomen.

${ }^{15}$ I Boyer 1994 optræder der enkelte referencer til Keil 1979. Boyer anvender Keils apparat uden henvisning til eller behandling af den filosofiske baggrund. Sommers teori er en bearbejdelse af dels Bertrand Russells typeteori, dels af Gilbert Ryles kategoriteori. Fred Sommers udviklede en teori om forholdet mellem sprog og
} 
losofisk teori og gjorde den til et psykologisk nativistisk projekt, som Boyer derefter adopterer og bruger til at tilbagevise det sprogliges (og dermed det sociales) betydning. Det er næsten for sælsomt.

\section{Primitiv epistemologi/scientisme}

Boyer refererer entusiastisk biologen Richard Dawkins teorier om kultur som 'memers' invasion i og kolonisering af en population. Boyer bruger teorien, som var den ontologisk eller epistemologisk på niveau med genetikken, og han gør det tilsyneladende uden at bekymre sig om teoriens sociale eller kulturelle aspekter. Trods de kognitive teoriers tilstræbte sofistikation forekommer Boyers videnskabsteoretiske standpunkt her nærmest naivt empiristisk. Han har ingen problemer med at afgøre, hvad der er virkelighed, og hvad der er fiktion, for det mener han at kunne gøre ud fra den psykologiske karakteristisk af den 'intuitive ontologi'. Som et næsten besynderligt kritikpunkt (s. 40f) vil han gøre op med den antagelse (vi får ikke at vide, hvem der har den), at kulturtilegnelse og dermed enhver tilegnelse af information er en passiv proces. Boyer understreger, at den menneskelige hjerne er aktiv i udvælgelsen og behandling af information, kort sagt, i et lidt andet sprog, at vi fortolker. Den mageløse afsløring af, at vi ikke er 'rå induktivister', men fortolkende væsener, burde ikke kunne frembæres som noget nyt. Glosen 'interpretation' findes ikke i indeks, og det er nok fordi den i visse kognitionsteoretiske kredse er et fyord, som lugter af humanistisk tradition med 'Verstehen' og 'Einfühlung ${ }^{16}{ }^{16}$ Når Boyers subjekter tænker og fortolker, gør de det i 'computations' og 'inferential processes'. Hvis man ikke er helt sikker på en sag, er det på grund af en vis 'plasticity of ontological commitments'. Sådan kan man også sige det.

For Boyer kan alt løses empirisk og med naturvidenskabelige metoder. Det vil sige, at hans standpunkt ligger tæt på det, som filosoffen Quine kaldte 'naturaliseret epistemologi', at erkendelsesteori udelukkende handler om, hvad videnskaben kan fortælle os om verdens indretning og derfor ikke omfatter normative spørgsmål. Hos Boyer (2000) bliver denne opfattelse individualiseret og psykologiseret, og så handler det ikke længere om videnskaben som epistemisk projekt, men om den enkeltes kognitive apparat. Den 'naturaliserede epistemologi' er problematisk nok, men hos Boyer bliver den tilmed

verden, som også kan være religionsvidenskabeligt interessant, se Englebretsen 1997. Sommers sprogteori er samtidig en teori om underliggende konceptuel viden, hvor "categories demarcated linguistically by predicability are isomophic to ontological or conceptual categories" (Keil 1979, 161). Det kan sagtens udvikle sig til noget rod, når man på denne letsindige måde giver sig i kast med nogle af de mest tunge filosofiske problemstillinger, her relationen mellem sprog, bevidsthed og verden. I øvrigt synes Ryles ideer om begrebers betydning som brug og om kategorifejltagelser også at have en skjult plads hos Boyer, som selv ikke forekommer at være bevidst om sit filosofiske stamtræ og dets betydning.

${ }^{16}$ Den indstilling låner han fra Sperber, som netop har kritiseret antropologien for at være 'interpretive' i stedet for 'explanatory', for kun det sidste er videnskabelig lødigt. F.eks. er en fortolkning af et symbol kun ('ikke andet end') en udvidelse af symbolets betydningsfelt, og dermed ikke nogen forklaring. Se f.eks. kap. 2 i Sperber 1996. Det er en sær vending, hvormed man fraskriver al fortolkende forskning dens videnskabelighed, men det hænger sammen med den scientistiske beundring for naturvidenskab (hvor Sperber åbenbart tror, at der ikke fortolkes). 
individualiseret. Han er også en slags 'primitiv realist', for ellers kunne han vel ikke appellere til 'intuitiv ontologi' som den øverste instans for spørgsmål om, hvad der findes, og hvordan det uproblematisk kan skelnes fra illusion og fiktion. Men det er nok et spørgsmål, han bare ikke kerer sig om. I hans epistemologi er problemet om forholdet mellem input og output blevet løst - eller er det? En beskrivelse af kognitive mekanismer er ikke nogen adækvat afløsning for erkendelsesteorien. ${ }^{17} \mathrm{Og}$ da slet ikke med de problemer, som kognitionsforskningen har alene i forbindelse med afgrænsningen af sit teoretiske objekt.

Epistemologi er ikke kun et individuelt fænomen, men Boyer synes at have mistet forståelsen for, hvad det betyder, at videnskab er et intersubjektivt anliggende. Det allermest interessante er netop, at videnskaberne, dvs. forskere, er nødt til at bruge ikke bare tekniske instrumenter, men nok så meget 'bevidsthedseksterne' objekter (tegn, begreber, modeller osv.), som ikke eksisterer fysisk, for overhovedet at kunne skabe nogen erkendelse af det, som er materielt, fysisk osv. Det kan netop kun lade sig gøre, fordi videnskab er en livsform, der er stærkt abstrakt og symbolbrugende. Og hvor går i grunden grænsen mellem forskeren, hendes bevidsthed og forskningen? Det er i alle tilfælde ikke ved epidermis. ${ }^{18}$

\section{Evolution og kultur}

Boyers udviklingshypotese indeholder endvidere det problem, at hans nativistiske kognitionsteori er problematisk i forhold til neurovidenskaben, som ikke kan underbygge de nativistiske teorier om f.eks. særligt menneskelige 'sprogkredsløb', medfødt grammatik eller lignende - ganske enkelt fordi der ikke har været tid nok i evolutionen til, at noget sådant skulle kunne udvikle sig. ${ }^{19}$ Boyer ønsker at fundere vores medfødte intuitive ontologi i evolutionen, men ideen kan ikke være meget andet end en hypotese på det foreliggende grundlag - men det ville i grunden også have været interessant nok. En del af hans eklekticisme beror på blandingen af evolutionære forklaringer og kognitiv psykologi. Hans antagelse af, at visse psykologiske størrelser er almene, er problematisk, netop fordi de skulle være optimale i tilpasningen - det ligner naiv adaptionisme - og under alle omstændigheder er det en cirkelslutning. Kultur (som han jo alligevel ikke kan afskaffe) bliver således til resultatet af en "selektion som finder sted hele tiden og alle vegne" (s. 33). Det er vanskeligt at modbevise og derfor er det måske slet ikke noget videnskabeligt udsagn (jf. kriterier for falsifikation). Og så er det ærgerligt, at Boyer standser dér, hvor kulturen begynder. Historie elimineres også i hans værk, for der er ingen hensyn til de større overgange i artens historie og udvikling, som f.eks. den agrare revolution, og det er underligt, for han er dog også social-antropolog. Alligevel

\footnotetext{
${ }^{17}$ Det kan der siges meget om - uenigheden er stor og det er efterhånden en gammel diskussion. Se f.eks. "Is Epistemology Possible" i Dancy 1985, 227-42.

${ }^{18}$ Se bl.a. Clark 1997, især s. 193-218 om det problematiske i det traditionelle skel mellem sprog og bevidsthed. Hans opfattelser går stik imod Boyers, og da de nu er ansat på samme universitet kan vi måske vente en (vis) afklaring af problemet.

${ }^{19}$ Diskussion af denne problematik findes bl.a. i Deacon 1997.
} 
forsøger han sig med økonomiske rationaler i forklaring på opkomsten af de særlige religiøse eliter, men det bliver så ud fra en evolutionært grundet ide om byttemaksimering og 'rational choice'. Den valgte videnskabsform forhindrer igen beskæftigelsen med noget, som ligger over eller uden for det enkelte individ.

Boyer er en typisk 'bottom-up' teoretiker og af den mere radikalt materialistiske slags. Han forsøger at aflive eller afskaffe de fleste højere-ordens fænomener som f.eks. kultur, enten ontologisk eller epistemisk. Dvs. enten som ikke-eksisterende, eller som noget 'der ikke betyder noget'; noget som ikke har nogen kausalitet, og som derfor ikke kan være årsag til noget andet. Det hører med til hans videnskabsforståelse med dens forkærlighed for naturvidenskabelige metoder, at forklaring udelukkende betyder kausal forklaring, og at forklaring af fænomener på højere niveauer skal søges på de lavere, f.eks. når biologiske fænomener forklares på kemisk grundlag. Men muligheden for at kunne give kausale begrundelser og forklaringer på et lavere niveau, betyder ikke, at de højere niveauer ophører med at eksistere. Således behøver religion ikke være blevet forklaret (væk?), selv om man kan give en udstrakt kognitiv forklaring på mange aspekter af det, som vi sædvanligvis forstår ved religion. Værre er det, at når religion er blevet reduceret til religiøse forestillinger produceret af hjernen, tildeles disse en status som epifænomener, dvs. at de er ude af stand til at virke tilbage på det, som de er produceret af: forestillinger er ('ikke andet end') mentale fænomener, og hvordan skulle de kunne have en kausal effekt på noget materielt? Men dette stærkt dualistiske og meget traditionelle epifænomenalistiske syn giver store forklaringsproblemer på det sociale niveau, for hvad består f.eks. en motivation af? Har ritualer slet ingen virkninger ud over de mentale?

Det er noget af et problem, hvordan man så i øvrigt skal foretage strengt nomologiske og kausale forklaringer med de løse begreber, som han til dels selv definerer (også uklart) som 'domæne', 'kategori', 'repertoire'. Dertil kommer, at vi faktisk ikke rigtig ved, hvad kognition er, eller hvor den ligger, for kognition er ikke nogen entydig størrelse, heller ikke selv om det skulle lykkes at udarbejde et entydigt begreb om den. Som anden videnskab betjener kognitionsforskning sig af analytiske begreber, der ikke refererer direkte til empiriske sagsforhold, såvel som af heuristiske metaforer og imaginære modeller. Der er ingen grund til at falde på halen over Boyers empiricisme. Tværtimod må man sige, at den i erkendelsesteoretisk forstand er lige så kritisabel som megen anden kognitionsforskning, der er afhængig af ideer om forestillinger ('representations') som mødestedet mellem eksterne objekter og hjernen, og om at intentionalitet består i eller kan reduceres til kausale påvirkninger fra det, vi tænker på. ${ }^{20}$

\footnotetext{
${ }^{20}$ Den filosofiske kritik synes ikke at slå igennem i kognitionsforskningen, men se herom f.eks. Putnam 1999, kap. 4 "The face of cognition" hvor han bl.a. siger: "mind talk ... is best understood as talk of certain abilities we possess, abilities that depend upon our brains and upon all the various transactions between the environment and the organism but that do not have to be reductively explained using the vocabularies of physics and biology, or even the vocabulary of computer science" (s. 44).
} 
8. Religionspsykologi - og måske religionsfilosofi - på 'biologisk grundlag'

Religion er parasitær, siger Boyer (s. 191 og 311), og da den har epifænomenkarakter, kan religiøse begreber ikke virke tilbage på kognitionen, og der er derfor intet 'feedback’. Så hvis religion forekommer at være menneskeligt vigtig, er det kun tilsyneladende, for i virkeligheden sker der ikke andet end, at religion, forstået som religiøse mod-intuitive forestillinger, aktiverer vores almindelige (ikke-religiøse) kognitive inferenssystemer optimalt. Dermed kan man sige, at selv om Boyer anvender masser af religionsempiri, er hans teoretiske objekt, dvs. målet for hans forskning, ikke religion, men alene nogle bestemte kognitive processer. Hans religionsbegreb og interesse begrænses derfor til hypotesen om ikke-observerbare agenters kognitive betydning og det er sådan set alt, hvad Boyer fokuserer på.

På sin vis er der et tilløb hos Boyer til en revideret religionspsykologi, men problemet er hans manglende referencer og relationer til den bestånde forskning. Springet til Boyers paradigme bliver stort, og så mangler han andre relevante emner som emotion og intentionalitet, de social-psykologiske aspekter osv. Kort sagt, Boyers værk kan blive et bidrag til en ny religionspsykologi, men der skal mere til (Pyysiäinen 2001 og Hinde 1999). Det er Boyers ambition at lave en rent empirisk og teoretisk fremstilling af, hvad der grundlæggende kan siges at konstituere religion - de mod-intuitive forestillinger. Projektet handler også om muligheden for at formulere en (psykologisk begrundet) opfattelse af religion, som er teoretisk plausibel og ikke-kulturbundet, eurocentrisk osv. ${ }^{21}$ Det lykkes på sin vis, men han ender selv i noget højst spekulativt - måske også som en slags religionskritik. Det ser ofte ud som om, han ganske enkelt ikke kan 'li' religion, han er en af dens 'dannede foragtere' . Et eksempel herpå er, når han forklarer, hvorfor hans egen forklaring af, hvorfor katolikker går til messe, er troværdig ('den producerer særlige effekter ved at aktivere særlige systemer i den mentale kælder'), mens deltagernes egne motivationer er ugyldige eller ligegyldige som forklaring. Han glemmer, at begge kan have noget på sig, men det hører (igen) med til hans videnskabssyn, at en begrundelse ikke kan være en forklaring (hvad der selvfølgelig forekommer de fleste meget mærkeligt, men der er en filosofisk tradition bag denne opfattelse).

I Boyers fremstillingsmetode er det karakteristisk, at han gennemgår lange forklaringer af noget, hvor læseren får at vide, at det alligevel ikke dur, og derefter foreslår han noget andet (som heller ikke altid dur), f.eks. hans eliminativistiske bortskaffelser af betydning, kultur, sprog og andre emner, som normalt har social- og humanvidenskabernes interesse. I den forstand er det en kompliceret bog; en sindrigt udtænkt kæde af hypoteser. Men kæder er nu en gang ikke stærkere end de svageste led, og dem er der altså nogle stykker af her. Endelig bør det nævnes, at en del af hans bemærkninger om og brug af elementer fra religiøse traditioner (f.eks. kristendom, jødedom osv.) er ganske sære. Problemet er nok, at han i grunden ikke er særlig velbevandret i religionshisto-

\footnotetext{
${ }^{21}$ Se her Boyer \& Ramble (2001) om eksperimenter, de har udført i Gabon og Nepal, og som viser ensartet respons på mod-intuitive informationer - uafhængigt af forskellene i religionstilhørsforhold.
} 
rie eller -antropologi generelt. Men igen det er svært at afgøre når alt, hvad han selv gør, er at afvise hidtidig forskning.

\section{Relevans og anvendelse}

Boyers relevans ligger ikke mindst $i$, at han er højst irriterende og derfor vækker til eftertanke omkring mange af de selvfølgeligheder, som forskningen - og ikke mindst religionsforskningen - traditionelt har hvilet på. Men i processen får han så også gjort religion til et epifænomen, der ikke har nogen videre videnskabelig interesse, efter at det nu er blevet forklaret. Og det er ganske mærkværdigt, for faktisk er det 'mod-intuitive' et fremragende analytisk redskab uanset de problemer, der måtte være involveret $i$ at ville gøre det til mere end et analytisk redskab f.eks. ved at antage, at den intuitive epistemologi er medfødt, og at kategorierne og domænerne har direkte ontologisk reference.

I øvrigt er det videnskabssociologisk interessant, at man omkring Boyers forfatterskab har kunnet se, hvordan en kreds af forskere etablerer en platform - hvordan menigheden konstrueres. Med en prominent ældre britisk forskers ord er kognitionsteori i religionsforskning domineret af 'en gruppe amerikanere som citerer' hinanden. Der er lidt om snakken. Bag på den amerikanske udgaves smudsomslag udtaler Dan Sperber: 'Pascal Boyer is the world expert on religion and cognition...' Nok også fordi Boyer i den grad har promoveret Sperbers noget idiosynkratiske teorier. Det er rigtigt, at Boyer indtil videre er en af de mest artikulerede om forholdet mellem kognition og religion, men han skal nu ikke have lov til at stå alene som repræsentant for kognitionsteoretisk religionsforskning. Der er andre, som følger samme spor som Boyer, f.eks. Ilkka Pyysiäinen (2001) og Scott Atran (2002). Problemet er, at de fleste, som har forstand på f.eks. psykologi, kognition, evolution og biologi normalt slet ikke er interesserede i religion som et videnskabeligt objekt. Nogle er måske personligt interesserede, men det er en anden sag og en, hvor man bidrager til religiøsiten snarere end til religionsvidenskaben. Boyer bidrager til det sidste, og det gør han sine steder godt. Men bare det dog ikke skulle være så polemisk og teoretisk afstumpet. Det gør ikke noget at indrømme, at man ikke ved alt. Det er da bedre end at lade som om, at al anden forskning ikke eksisterer. En mere åben attitude hos paradigmets standartbærere ville måske ligefrem kunne bidrage til en udbredelse af budskabet.

\section{Litteratur}

ATRAN, SCOTT

2002 In Gods We Trust. The Evolutionary Landscape of Religion, Oxford.

BOYER, PASCAL

1990 Tradition as Truth and Communication. A cognitive description af traditional discourse, Cambridge.

1994 The Naturalness of Religious Ideas: A Cognitive Theory of Religion, Berkeley, CA.

1998 "Cognitive Tracks of Cultural Inheritance: How Evolved Intuitive Ontology Governs Cultural Transmission", American Anthropologist Vol. 100, No. 4, 876-89. 
2000 "Natural epistemology or evolved metaphysics? Developmental evidence for earlydeveloped, intuitive, category-specific, incomplete, and stubborn metaphysical presumptions", Philosophical Psychology Vol. 13, No.3, 277-97.

2001 Religion Explained. The Evolutionary Origins of Religious Thought. New York

2003 "Religious thought and behaviour as by-products of brain function", TRENDS in Cognitive Science Vol. 7, No. 3, 119-24.

Boyer, PASCAL \& Charles RAMBLE

2001 "Cognitive templates for religious concepts: cross-cultural evidence for recall of counterintuitive representations", Cognitive Science 25, 535-64.

Clark, ANDY

1997 Being There. Putting Brain, Body and World Together Again, Cambridge, MA.

DANCY, JONATHAN

1985 Introduction to Contemporary Epistemology, Oxford.

ELMAN, JEFFREY, et al.

1996 Rethinking Innateness. A Connectionist Perspective on Development, Cambridge, MA.

ENGLEBRETSEN, GEORGE

1997 "Religious discourse and Sommer's theory of truth: A response to Hans H. Penner", Method and Theory in the Study of Religion, Volume 9-3, 249-58.

HINDE, ROBERT A.

1999 Why Gods Persist. A Scientific Approach to Religion, London.

KeIL, FranK C.

1979 Semantic and Conceptual Development. An ontological Perspective, Cambridge, MA.

McCauley, Robert N. \& E. Thomas Lawson

2002 Bringing Ritual to Mind. Psychological Foundations of Cultural Forms, Cambridge.

PUTNAM, HILARY

1999 The threefold cord mind, body, and world, New York.

PYYSIÄINEN, ILKKA

2001 How religion works: towards a new cognitive science of religion, Leiden.

SPERBER, DAN

1996 Explaining Culture. A Naturalistic Approach, Oxford.

WhITEHOUSE, HARVEY

2000 Arguments and Icons: Divergent Modes of Religiosity, Oxford.

\section{Summary}

This review article was occasioned by the publication of Pascal Boyer's Religion Explained. The Evolutionary Origins of Religious Thought (2001), the title of which left this reviewer in some doubt and intent on investigating whether Boyer's ambition has been fulfilled. Here, it must be noted that this reviewer is generally positive about the rewarding aspects of the 'cognitive turn' in the study of religion and Boyer's earlier substantial contributions to this, but he is also wary of the fallacy of 'partial explanation': explaining a part does not amount to an explanation of the whole.

After a presentation of the reviewer's perspective and involvement in a research group working on religious narrative, cognition and culture, a substantial step-by-step review of the contents and structure of Boyer's argument is presented. Then follows a discussion of the central concepts of domain specificity concerning cognitive representations and the 'counter- 
intuitive' nature of religious thought and, further, Boyer's subsequent ideas concerning rituals and the ramifications for social formations and historical developments in what he calls 'The Full History of All Religion (ever)'. Next, the reviewer offers some 'critical intuitions' and questions the return of (a new mode of) psychologism in the human sciences and Boyer's dependence upon earlier theorizing which is not clearly noted nor acknowledged, but which has consequences for the epistemic status of his project and for those who follow the same tracks in the cognitive study of religion. It turns out that the methodology is based on extreme individualistic and scientistic attitudes, where 'higher-order' theoretical objects are explained (away?) by lower-order phenomena. In short, Boyer (and others) stops where culture begins and, as a consequence, religion is transformed into an epiphenomenal category without any causal effects. In the chosen theoretical perspective, religions 'mean' nothing; there exist 'nothing but' the cognitive representations of individual individuals - but in this manner, the currently dominating approach in the cognitive study of religion perpetuates a Cartesian mystique and a dubious physicalist dualism concerning the mind and the objects it 'cognizes'. Cognitive theory is definitely an advance in the study of religion but it takes more than materialist fideism to make it convincing. The work of language, culture etc. has to be accounted for more seriously and in more detail.

Jeppe Sinding Jensen

Lektor, cand.mag.

Afdeling for Religionsvidenskab Aarhus Universitet 